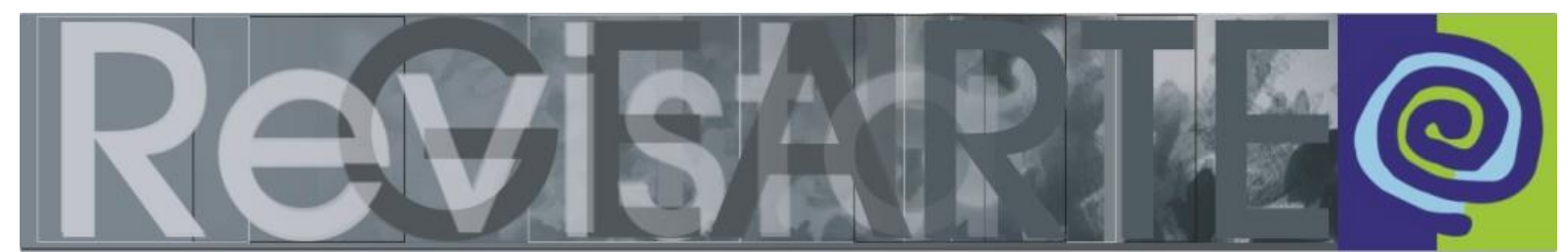

ISSN 2357-9854 | e-ISSN 2596-3198 (online)

\title{
Decolonialidade versus algoritmo: formação e ampliação do repertório imagético dos arte/educadores
}

\author{
Julia Rocha $(i)$ \\ (Universidade Federal do Espírito Santo - UFES, Vitória/ES, Brasil) \\ Any Karoliny Wutke Souza \\ (Grupo de Pesquisa Entre - Educação e arte contemporânea - UFES, \\ Vitória/ES, Brasil)
}

\begin{abstract}
RESUMO - Decolonialidade versus algoritmo: formação e ampliação do repertório imagético dos arte/educadores - Ao refletir sobre a formação e ampliação do repertório imagético dos arte/educadores, este texto analisa o enfrentamento que as discussões em torno dos estudos decoloniais encontram na lógica dos algoritmos que operacionalizam os mecanismos de busca online. O aplicativo Google Arts and Culture é analisado como possibilidade de pesquisa, demonstrando potencialidades da ferramenta na formação continuada dos educadores. Em contrapartida, a restrição dos algoritmos e a limitação do banco de imagens construído a partir das coleções de museus de arte impedem a construção de um olhar que amplie a abrangência de artistas que estejam fora do eixo dominante instituído pela história da arte.
\end{abstract}

PALAVRAS-CHAVE

Arte/educação. Professor. Formação. Repertório imagético. Estudos decoloniais.

\begin{abstract}
Decoloniality versus algorithm: formation and expansion of the imagery repertoire of art/educators - When reflecting on training and expansion of the imagery repertoire of art/educators, this text analyzes the confrontation that discussions around decolonial studies find in the logic of the algorithms that operationalize online search engines. The Google Arts and Culture application is analyzed as a research possibility, demonstrating the tool's potential in the continuing education of educators. On the other hand, the restriction of algorithms and the limitation of the image bank built from art museum collections prevent the construction of a view that broadens the scope of artists who are outside the dominant axis established by art history.
\end{abstract}

KEYWORDS

Art education. Teacher. Training. Imagery repertoire. Decolonial studies.

RESUMEN - Decolonialidad versus algoritmo: formación y expansión del repertorio de imágenes de los profesores de educación artística - Al reflexionar sobre formación y expansión del repertorio de imágenes de los profesores de educación artística, este texto analiza la confrontación que las discusiones en torno a los estudios decoloniales encuentran en la lógica de los algoritmos que operacionalizan los motores de búsqueda en línea. La aplicación Google Arts and Culture se analiza como una posibilidad de investigación, demostrando el potencial de la herramienta en la formación continua de los educadores. Por otro lado, la restricción de los algoritmos y la limitación del banco de imágenes construido a partir de las colecciones de los museos de arte impiden la construcción de una mirada que amplíe el alcance de los artistas que se encuentran fuera del eje dominante que establece la historia del arte.

PALABRAS CLAVE

Educación artística. Profesor. Formación. Repertorio de imágenes. Estudios decoloniales.

ROCHA, Julia; SOUZA, Any Karoliny Wutke. Decolonialidade versus algoritmo: 


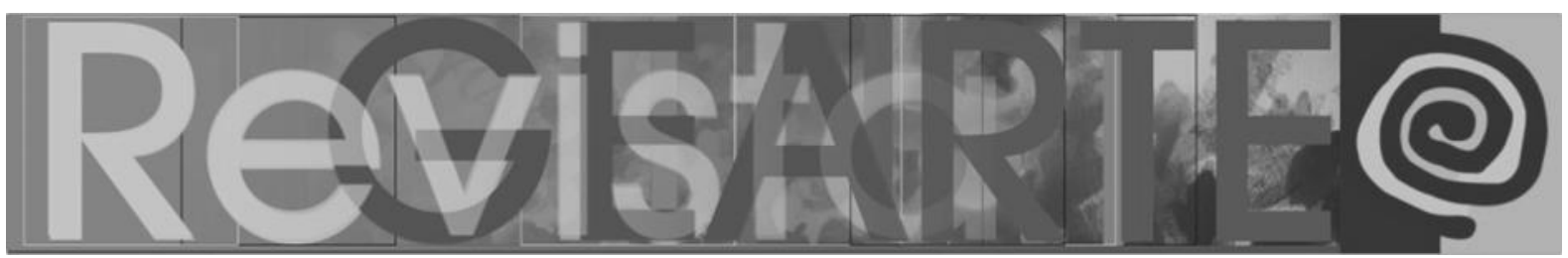

No processo de formação dos arte/educadores e, posteriormente, em sua atuação na docência do ensino da arte, perpassam diferentes momentos de construção de um repertório de imagens. Inicialmente, esse repertório é formatado no curso de graduação, Licenciatura em Artes Visuais, por meio das disciplinas teóricas e práticas. Esse repertório é construído e ampliado durante toda a formação enquanto sujeito, acumulando as referências elaboradas a partir de tudo o que é consumido, lido e criado em termos de imagem. E, após concluída a graduação, essa formação continua em desenvolvimento, atuando perenemente na ampliação do repertório de imagens do arte/educador.

O presente texto analisa a importância do alargamento do conjunto de referências que compõem o repertório dos professores de artes visuais, sugerindo, como objeto de análise, as pesquisas sistematizadas possíveis de serem construídas com o aplicativo Google Arts and Culture. Parte-se da apresentação das potencialidades que essa ferramenta apresenta para os processos de estudo e planejamento dos professores, identificando que funcionalidades podem ser produtivas para investigações elaboradas na atuação docente. Em contrapartida, o texto também discorre sobre as limitações do aplicativo, sobretudo no que diz respeito ao conjunto de referências que seu banco de dados consegue abarcar e à armadilha que os algoritmos criam a partir do histórico de pesquisa, recaindo em um conjunto de imagens limitado e restrito ao repertório dominante da história da arte.

\section{A formação do repertório de imagens}

Ao considerar a formação do repertório de imagens como um processo constante, que ocorre antes mesmo do ingresso no ensino superior, compreendese que esse conjunto se amplia constantemente, sendo elaborado de maneira ativa e passiva. A passividade está presente na vivência do mundo de imagens que coabitamos, no qual somos continuamente assediados por elas (ACASO; MEGIAS, 2017). Dessa forma, ainda que consumidas de maneira passiva, elas perpassam a construção do olhar que estabelecemos para o que nos cerca e, 


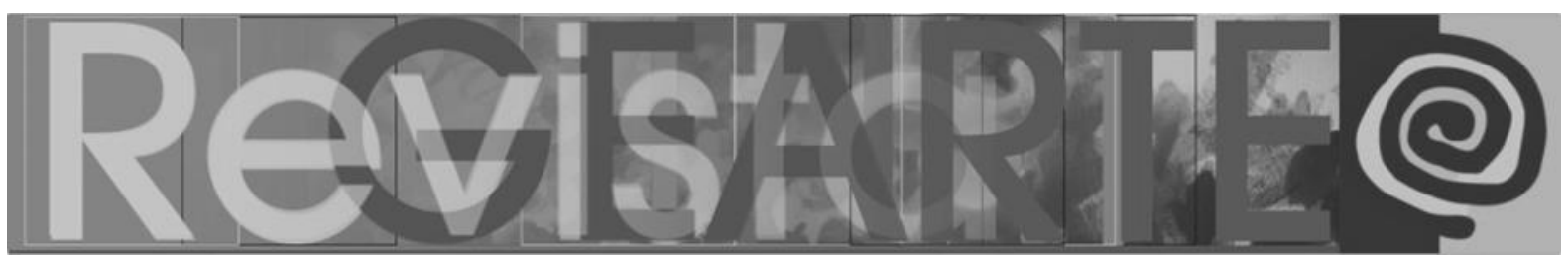

nesse sentido, María Acaso e Clara Megías (2017, p. 52) demarcam que "[...] as imagens são símbolos que nos percorrem, que produzem mudanças na nossa maneira de entender a vida e vivê-la".

O consumo de imagens se amplia continuamente pelas possibilidades de acesso que temos por meio das tecnologias digitais. Acaso (2009) destaca a relação de aproximação com os mecanismos de propagação que passamos a carregar nos bolsos, demarcando como é assustador que em cinquenta anos nossa relação do acesso às imagens se ampliou imensamente, visto termos os celulares e smartphones modificando as possibilidades de consumo e produção delas. A autora deflagra que esses equipamentos nos permitem "[...] não somente estar em contato oral com o resto do mundo, mas fazer fotos e vídeos e compartilhar essas representações visuais com quem desejarmos e em tempo real" (ACASO, 2009, p. 27).

Ainda, no que diz respeito à passividade no consumo das imagens, Acaso (2009, p. 32) diz que "[...] nesse tipo de sociedade os indivíduos, deslumbrados pelo espetáculo, submergem em uma existência passiva, aspirando somente adquirir a maior quantidade possível de produtos para posteriormente exibir a compra imediatamente". Aqui, encontra-se um ponto de transição, pois a posição passiva de consumo se torna ativa na medida em que nos vemos partilhando com outros sujeitos aquilo que consumimos. "Já não se sente prazer ao contemplar as imagens, sinto prazer somente quando as compartilho com outros" (ACASO, 2009, p. 32). O desenvolvimento das redes sociais marcou esse processo de mudança, visto que na possibilidade de propagação das imagens está, também, outra forma de se relacionar com as mesmas, para além do consumo e da criação.

Assim, existe, ainda, o consumo imagético ativo, elaborado a partir dos produtos visuais que são absorvidos por eleição, como produtos da cultura visual, como as exposições, os catálogos, as visitas aos lugares promotores da imagem, os filmes, os programas de televisão e os vídeos compartilhados em redes sociais. 


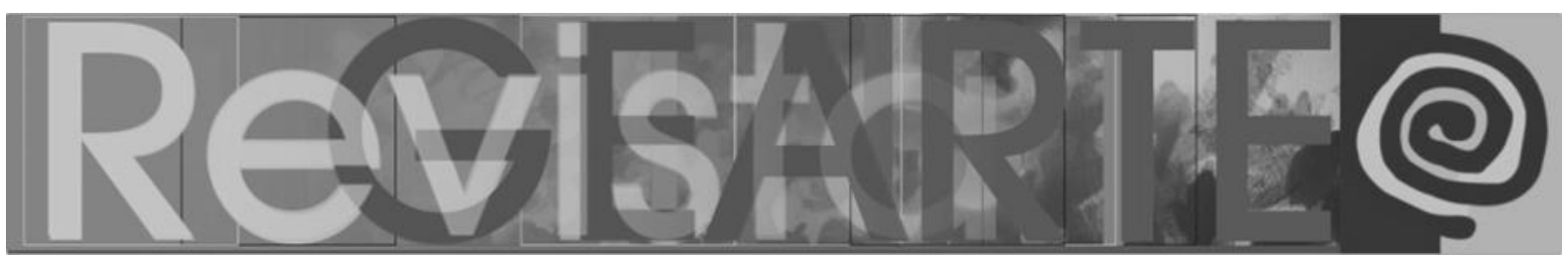

Para um arte/educador, essa construção ativa do repertório ocorre por meio da pesquisa e em diferentes âmbitos do consumo de imagens do campo da arte, da cultura visual ou de outras fontes. O professor forma seu repertório a partir de variadas perspectivas, como visitas a museus e espaços culturais, consulta e estudos de revistas e livros da área, participação em cursos de formação continuada, pesquisa em sites que fomentem a arte e possibilitem a ampliação do conjunto de imagens que retém para seu recorte imagético e pedagógico, bem como na troca entre os sujeitos envolvidos na prática educativa. Marcelo Forte (2011, p. 834) disserta sobre essa construção, descrevendo diferentes circunstâncias na qual se forma o olhar do arte/educador:

Ao se reportar ao repertório visual produzido, o professor de artes visuais encontra as imagens colecionadas, estudadas durante o curso, suas próprias produções, bem como aquelas imagens que estiveram presentes em outros eventos, como a ida até o cinema, que além da narrativa fílmica, estiveram presentes imagens do lugar, das pessoas, das ruas que o levaram até o local, ou então as compras em um supermercado onde cada corredor o prendeu por um tempo maior ou menor, pelas cores das embalagens, formatos, distribuição e alinhamento e assim identifica um acervo imagético que se dilui entre tantos outros pensamentos e imagens e que se solidifica ou se manifesta em outros espaços.

A construção constante de um repertório imagético se consolida no olhar crítico para as imagens, integrando a pesquisa ativa ao consumo passivo daquilo que cerca os sujeitos. E, nesse sentido, qualquer momento pode ser pensado como um exercício para ampliação do repertório imagético, porque consideram-se não somente as imagens próprias do campo da arte, mas igualmente aquelas que compõem o sistema da publicidade, as manifestações políticas, a constituição dos espaços, as informações das indústrias de moda e design, a elaboração de sinais gráficos de rua e a comunicação dos veículos de mídia, para citar algumas possibilidades.

Ao pensar na formação durante a atuação do arte/educador na docência, considera-se que, no exercício de ampliação do seu repertório imagético, o professor de artes visuais está não somente construindo seu planejamento e passando a definir que perspectivas da arte e da cultura abordará em suas aulas, mas também atentando para a formação que ocorre no diálogo com seus 


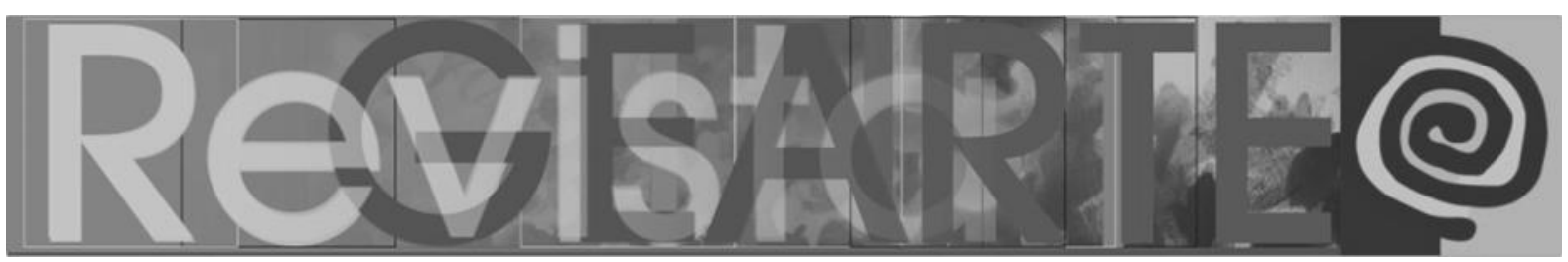

estudantes. Uma vez que representam distintos contextos de crescimento, variadas faixas etárias e diferentes escolhas no consumo das imagens, professores e alunos ampliam seus repertórios mutuamente, tendo como premissas da educação a prática partilhada e o diálogo construído no coletivo. $\mathrm{Na}$ perspectiva de uma educação descentralizada da figura do professor, a ampliação do repertório imagético se estabelece em um sistema de trocas, como sugere Forte (2011, p. 830):

\begin{abstract}
A formação docente está imbricada não somente na ideia de um professor detentor de saberes a serem repassados para os alunos, como talvez se tenha pensado um dia e que por vezes é encarado nos dias de hoje. Nesse momento em que vivemos, o professor adentra os espaços escolares imbuído sim de conteúdos, mas também os absorve nesses espaços, e um sistema de trocas pode acontecer entre professores, alunos e todo o corpo escolar na medida em que os caminhos vão sendo construídos.
\end{abstract}

Tendo em vista em que as trocas com os estudantes - e todo o corpo escolar, como situa Forte (2011) - são parte imprescindível do processo de formação continuada do professor, cabe atentar que um meio de identificação com os estudantes contemporaneamente se dá pela adequação dos modos de comunicação que se estabelece com eles. Diante disso, considerar o uso das redes sociais como mecanismos de interação e pesquisa é importante, inclusive, para a formação do repertório visual dos professores. Por meio do consumo imagético digital, o professor poderá identificar qual o rol de imagens da cultura visual que é consumido pelos alunos, visando a uma aproximação e buscando conexões que possibilitem que se construa, em sala de aula, o propósito de ampliar o repertório da turma.

\title{
O uso da tecnologia na ampliação do repertório imagético
}

As ferramentas virtuais não são exclusivas da geração em formação escolar, importante considerar, apesar de serem habitualmente mais próximas da vivência cotidiana dos nativos digitais. Contudo, professores utilizam-se, também, da internet como mecanismo de pesquisa para a construção de seus 


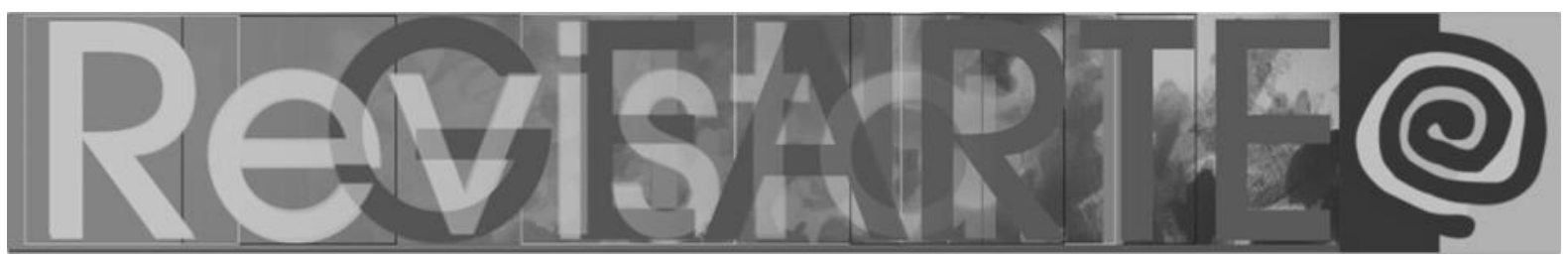

planejamentos, fazendo uso de ferramentas de busca para conhecerem mais artistas, aprofundarem pesquisas sobre determinadas linguagens das artes visuais, bem como construírem projetos que relacionem o que tiveram no seu percurso de formação com outros referenciais.

Para o trabalho, específico no campo da arte, uma potente ferramenta de pesquisa para o professor é o aplicativo Google Arts and Culture, um dos serviços do site de pesquisa que disponibiliza um grande banco de dados de imagens do campo da arte, além de oferecer uma série de funcionalidades que podem auxiliar o professor no planejamento e na atuação, constituindo-se como importante mecanismo para ampliação do repertório imagético.

Antes mesmo do desenvolvimento da extensão do Google dedicada ao mundo das artes, uma ferramenta se tornou de grande ajuda para o processo de trabalho dos arte/educadores. Em 2001, três anos depois do lançamento do que se tornaria o maior site de buscas e pesquisas, foi criada uma ferramenta específica para a busca de produtos visuais, o Google Imagens. Remontando a inseparabilidade entre imagem e consumo citada por Acaso (2009), essa ferramenta foi criada por conta do aumento do número de buscas por um vestido Versace utilizado pela atriz e cantora Jennifer Lopez na premiação do Grammy no ano 2000. O interesse dos espectadores da cerimônia pela autoria do vestido provocou o aumento das buscas online, contudo, o que continuamente se encontravam eram links para matérias em formatos de texto, sem conseguir acessar, em poucos cliques, a informação que desejavam buscar.

Assim, a relação entre desejo e consumo marcou a criação do desdobramento da plataforma de buscas especificamente voltada para as imagens. Hoje, as ferramentas de pesquisa imagética na plataforma se desenvolveram ao ponto de conseguirmos buscar respostas não somente a partir de verbetes, mas a partir das próprias imagens. A leitura dos elementos que as 


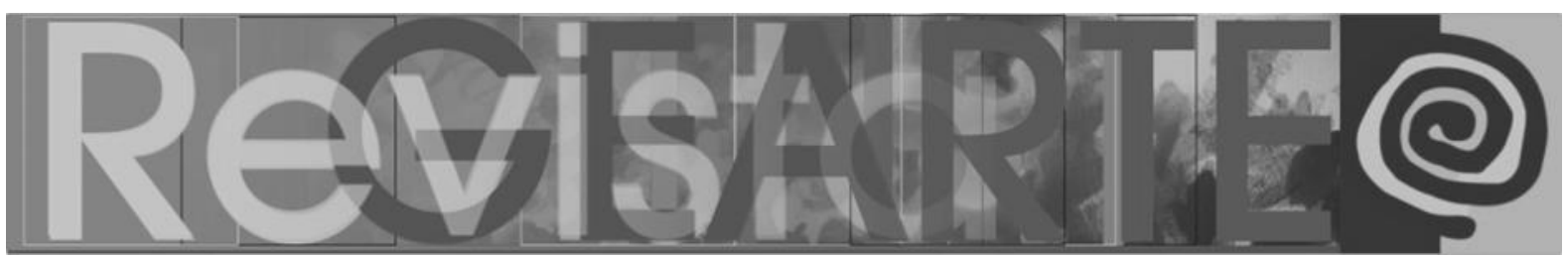

compõem permite identificar autoria ou chegar a resultados semelhantes em termos de cor, forma ou composição.

Dez anos depois, em 2011, foi desenvolvido o Google Arts and Culture, com o objetivo de criar ferramentas e tecnologias que possibilitem museus, galerias de arte e instituições culturais levarem seus acervos para além das quatro paredes das instituições e compartilharem suas coleções com uma audiência global. A primeira entrada de instituições brasileiras na plataforma foi em 2012 e, desde então, esse processo vem se ampliando, possibilitando que usuários da rede em geral, e arte/educadores especificamente, utilizem a base de dados como pesquisa e ampliação do repertório visual.

Se antes do aparato tecnológico um professor de artes visuais precisava, para acessar as imagens dos campos da arte e da cultura, recorrer aos livros que colecionasse ou aos quais tivesse acesso em bibliotecas, aos materiais educativos de exposições, aos museus que dispunham de pranchas de imagens ou a um acervo de slides e transparências que colecionasse, agora, ele encontra um número infindável de imagens disponíveis nos diferentes aparelhos digitais e mecanismos de busca. Esse volume exacerbado de imagens, contudo, pode recair em um amontoado sem sentido, se não houver uma sistematização e uma facilitação do acesso. Por isso, neste estudo, propôs-se a análise do Google Arts and Culture como uma das possíveis formas de acessar o banco de imagens disponível pela internet, por ser uma plataforma especificamente pensada para esse fim.

Diante do considerável conjunto de imagens possíveis de acessar por meio de pesquisa em sites, o aplicativo/plataforma do Google Arts and Culture se apresenta bastante adequado às necessidades de pesquisa do arte/educador, visto que dispõe - por meio dos filtros — de mecanismos de qualificação e refinamento das buscas. As galerias e coleções criadas dentro do aplicativo 


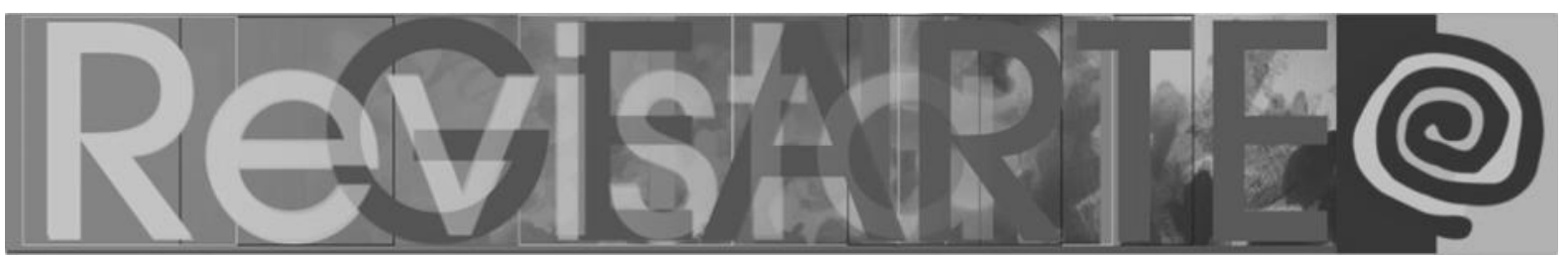

condensam imagens por temáticas, locais de origem, artistas, períodos, linguagens artísticas, dentre outras possibilidades de combinação.

Os modos de pesquisa disponibilizados pelo aplicativo são amplos, pode-se filtrar as imagens através de um recorte de espaço, tempo, cor, coleções e temas e comparar as produções dentro do recorte escolhido. A plataforma conta, ainda, com uma ferramenta que viabiliza a criação de sua própria galeria, o que permite que se desenvolvam categorias conforme suas especificidades, criando uma seleção personalizada que possa ter correspondência direta com um projeto específico de educação.

A utilização da plataforma permite uma experiência imersiva que pode ser inclusive superior à visualização presencial, visto que todas as imagens contidas no aplicativo são de alta qualidade, pois, com a ferramenta do Art camera, o registro das imagens é feito em gigapixel, ou seja, as imagens são formadas por um bilhão de pixels. Com isso, possibilita-se a utilização do Superzoom, que amplia a imagem sem haver perda da qualidade. Sendo assim, "[...] acessamos até mesmo as pinceladas que saltam do quadro como as dos impressionistas ou rachaduras do tempo das têmperas" (SOUZA, 2019, p. 57).

Pensando não somente no consumo passivo, mas na utilização ativa, o aplicativo conta com ferramentas em que há interação ou uso de realidade aumentada, como o Art selfie e o Art filter. O Art selfie, através de um retrato fotográfico, busca, em seu banco de dados, as obras que mais se assemelham com os traços do usuário. Já o Art filter produz filtros inspirados em obras nas quais o interator é retratado com a obra escolhida ao fundo. Se estiver diante de alguma obra que esteja no acervo, é possível, ainda, utilizar a câmera para identificar e colher mais informações sobre ela. No que tange à realidade virtual, é viável fazer visitas a alguns museus e galerias de diversos países em 360 graus, possibilitando não só observar as obras, mas o lugar no qual estão inseridas, ou mesmo projetar 


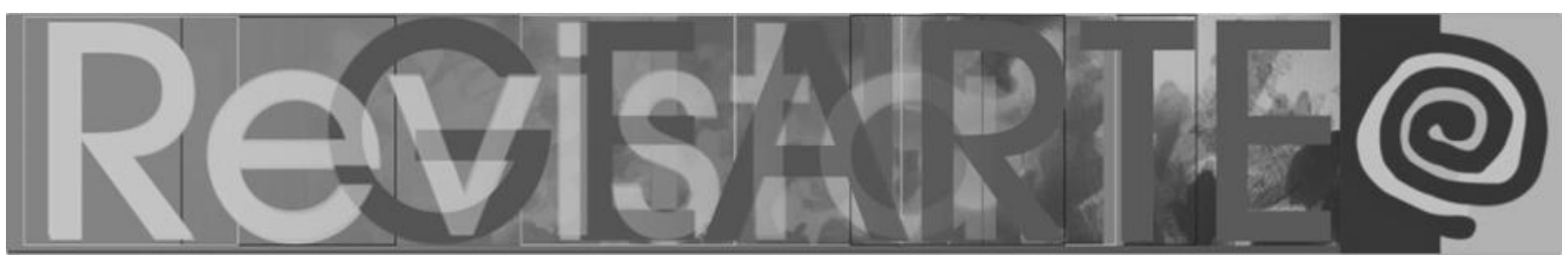

uma imagem no lugar físico onde o observador está, o que dá materialidade para o conjunto de imagens do banco de dados.

Pensando em ampliar o repertório para além das obras de arte, o aplicativo conta com uma seleção diária de conteúdos sobre diversos temas, incluindo a cultura visual, mas também abrangendo moda, design, gastronomia e cultura local de diversos países. O Google Arts and Culture está em constante desenvolvimento, consequentemente, suas ferramentas estão sempre mudando e em constante ampliação, o que aumenta as possibilidades de uso do aplicativo e a ampliação da formação do professor nesse sentido.

\section{Enfrentamentos entre algoritmo e decolonialidade na busca de imagens}

Em contrapartida a todas essas possibilidades de uso, o aplicativo Google Arts and Culture é acometido, também, por limitações no sentido da ampliação do repertório dos professores de arte. Na medida em que a ferramenta toma, como ponto de partida para seu banco de dados, as coleções de museus de arte, vemos que o aparente campo imagético bastante amplo começa a se limitar em um determinado recorte. As imagens adicionadas à coleção do aplicativo são tomadas a partir da inserção que instituições museais, artísticas ou culturais fazem na plataforma, agregando suas obras e ampliando as possibilidades de acesso e visualização.

Abrindo o convite de ingresso das instituições à plataforma, o Google gera a possibilidade de ampliação da coleção, visto que está disponível para todos que tenham acesso à internet, assim, a inserção de obras e imagens cresce à proporção que se ramificam os sujeitos autores do processo. Todavia, o que inicialmente poderia ser compreendido como um bom conjunto de referências visuais e uma razoável variedade no acervo, acaba resultando em um limitado conjunto de obras já consagradas ou já determinadas como produções legitimadas pelo sistema da arte, por serem obras e imagens presentes nas coleções dos museus. Conforme a política de aquisição de obras por essas instituições responde ao processo de dominação em relação às referências, identifica-se que os acervos 


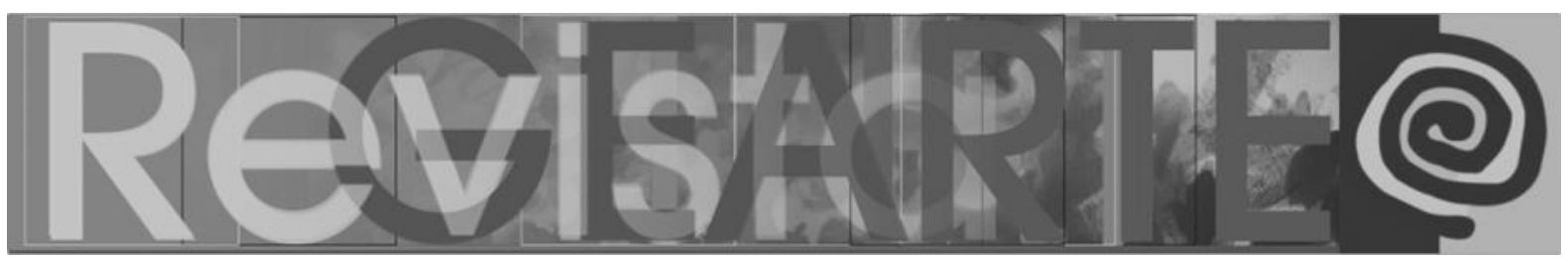

museais são um reflexo da política colonialista de aquisição de trabalhos de artistas ao longo da história da arte.

O recorte da produção artística e imagética representada nos museus é um reflexo de um processo de dominação cultural e epistêmica de anos, o que deflagra que as instituições não têm coleções que sejam representativas de diferentes lugares do mundo, além de concentrarem um determinado conjunto de produções que refletem as hierarquias de gêneros e linguagens do sistema da arte. A falsa sensação de ampliação das referências e facilidade no acesso acaba demarcando ainda mais as questões pertinentes aos processos de dominação que são desvelados com os currículos nulo ou oculto. A respeito do currículo nulo, Acaso (2009, p. 58) diz que o ocultamento de referências também nos faz aprender, demarcando o espaço da lacuna como informação:

\begin{abstract}
Imaginemos que estamos em uma aula de História da arte. As imagens de obras de artistas se sucedem a toda velocidade, enquanto que a escuridão da sala nos faz perder a noção de tempo. Seguimos, durante os quatro meses que dura a disciplina, vendo e comentando obras de arte, as grandes obras de arte da humanidade. Leonardo. Michelângelo, Picasso. Ao final, quando as luzes se acendem, os exames passem e a disciplina se encerre, somente temos como aprendizagem uma coisa: a incapacidade do gênero feminino para a criação artística, porque nenhuma das obras de arte que vimos foi produzida por nenhuma mulher. Portanto, temos aprendido mais do que não vimos, do que efetivamente do que vimos.
\end{abstract}

Essa realidade é marcante no processo formativo dos cursos de graduação, que, continuamente, contam uma história da arte dominante, centrada no eixo norte-global, androcentrada e branca. As aulas de história da arte - em minúsculas, para tratar da área como aberta, em oposição ao modelo vigente refletem o processo de dominação que as coleções dos museus tornam físicas. Assim, os livros, as instituições e as formações por elas promovidas reforçam o discurso da dominância, sem conseguir ampliar suas fontes em termos de gênero, de raça, de localização geográfica ou de classe. Continuamos vendo, no aplicativo Google Arts and Culture, a mesma história da arte a que fomos sempre submetidos durante todo o processo de formação. 


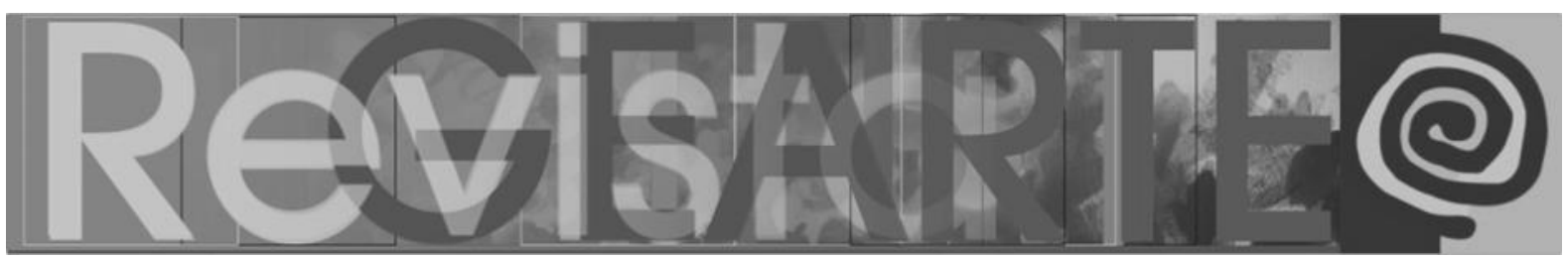

A questão é percebida na prática, uma vez que, para além da problemática do conjunto de obras que os museus detêm em suas coleções, outra questão apresentada em relação ao ingresso das imagens do banco de dados do aplicativo diz respeito ao feixe de instituições que a plataforma consegue atingir. Por exemplo, a pluralidade cultural e artística brasileira não é representada somente pelos espaços expositivos institucionalizados e, ainda assim, são poucos que estão inseridos no aplicativo.

No contexto do país como um todo, estão representadas, no Google Arts and Culture, apenas as coleções de 31 museus e instituições culturais ${ }^{1}$ e de arte $^{2}$ do Brasil. O conjunto de instituições está distribuído da seguinte forma: 15 do estado de São Paulo, 8 do Rio de Janeiro, 3 de Minas Gerais, 2 do Distrito Federal, 1 de Pernambuco, 1 do Paraná e 1 do Rio Grande do Sul. Diante das pluralidades históricas, sociais, artísticas, econômicas e culturais brasileiras, a representação de instituições em apenas 7 estados e a concentração de alguns deles demarcam a fragilidade do conjunto de imagens que o aplicativo acaba ofertando no contexto do país. Essa mesma perspectiva também é observada em relação ao grande número de instituições que representam países do hemisfério norte, demarcando uma dominação europeia e norte-americana.

Assim, mesmo se considerarmos que instituições como o Museu do Louvre, em Paris, o British Museum, em Londres e o Museu Metropolitan, em Nova York, têm uma representação grande da produção egípcia, andina ou oriental, a forma como a narrativa em torno das peças e imagens é feita é a partir do olhar do dominador, encarando essas culturas como o Outro, o inferior, o primitivo. A própria concentração das produções nesses locais é reflexo da história colonial vivida nos países do sul-global. A recorrência de imagens de povos originários sul-americanos, por exemplo, é a demarcação de um período de sofrimento e dominação que acaba resultando em uma coleção de imagens limitada e excludente. 


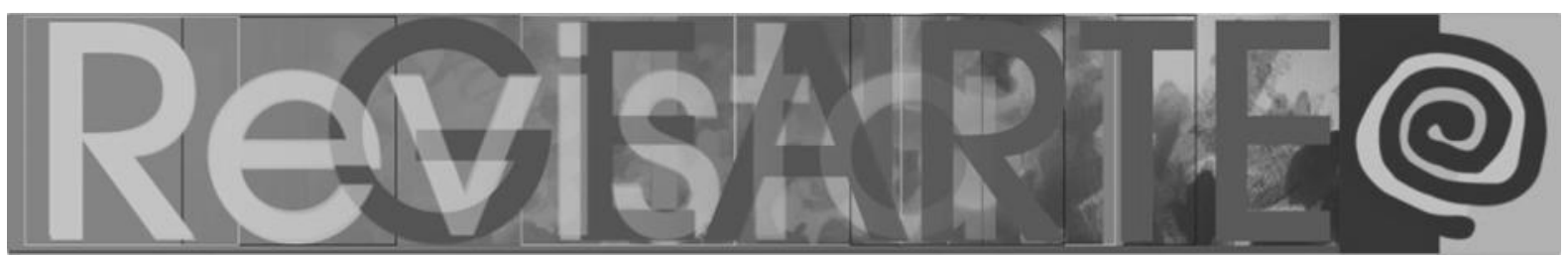

A discussão da necessidade de revisão das fontes bibliográficas que constituem a formação de professores e estudantes, que tem sido discorrida dentro da perspectiva de investigação da decolonialidade, entra em dissenso quando o banco de dados do aplicativo Google Arts and Culture reitera a dominação da produção artística proveniente dos contextos europeu e estado-unidense. Acaso (2009, p. 75) diz que "Refletir sobre por que um tipo de marco privilegia determinada informação visual ou por que se impõe ou não se expõe em uma vitrine fechada é refletir sobre o poder que se exerce através das representações visuais". Nesse sentido, ao invés de operar ampliando o repertório imagético do arte/educador para produções que estejam fora do eixo dominante na história da arte, o conjunto de imagens e a lógica operacional do aplicativo Arts and Culture reforçam o recorte da arte já circunscrito nos livros e reforçado pelas instituições museológicas.

O colonialismo identificado nas referências tomadas como fonte reforçam as estruturas de poder e de exploração da dominação epistemológica. Para Eduardo Moura (2017, p. 25), a colonialidade funciona como "[...] padrão de poder que opera pela naturalização das hierarquias territoriais, raciais, culturais e epistêmicas, possibilita a reprodução das relações de dominação e mantém abertas as feridas coloniais, que seguem profundas, infectadas e sangrando". O ato de negligenciar uma pluralidade de instituições ou de reforçar o caráter excludente que o processo de documentação da história da arte sacramentou acentua ainda mais a operacionalidade das estruturas de poder já existentes. Moura $(2017$, p. 28$)$ afirma que:

\begin{abstract}
A episteme eurocêntrica, única e excludente, já na constituição das primeiras universidades latino-americanas e na (con)formação docente em muitas instituições até a contemporaneidade, homogeneíza as formas de produzir conhecimento e de conhecer, de tal forma que a única versão de Arte ensinada e aprendida nos espaços educativos é europeia. As imagens que compõem o repertório, o imaginário e o saber docente são europeias.
\end{abstract}

Enquanto o processo de formação da maior parte dos professores em atuação se construiu nessa perspectiva de uma história da arte eurocêntrica com pequenas aberturas para a produção norte-americana -, a construção de um 


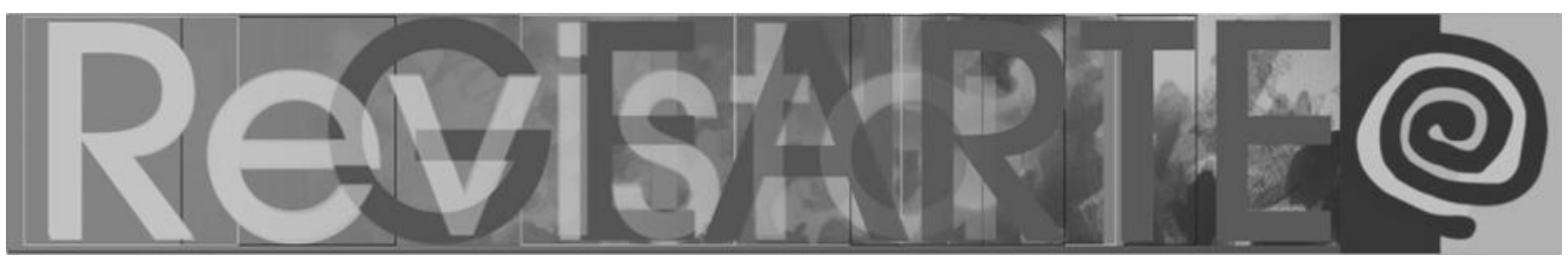

repertório imagético se manteve limitada, encerrada na construção de um olhar formatado e limitado do campo da arte. A lógica operacional dos algoritmos acaba, portanto, por reforçar esse recorte enviesado da produção imagética da humanidade, uma vez que os acervos dos museus e os livros que documentam a produção artística também se centram nesse olhar colonizado.

A necessidade de reformulação e de constante ampliação do repertório de imagens dos professores passa, ainda, pelos estudos decoloniais e pela necessidade de ultrapassar as limitações reiteradas pelos livros e pelas coleções dos museus. Não se está afirmando que todo o acervo do Google Arts and Culture seja circunscrito dentro da produção europeia ou norte americana, branca e masculina, até porque dentre as instituições brasileiras citadas temos espaços que buscam reconsiderar essa dominação. Mas, no aspecto quantitativo, ainda sobrepujam as imagens desse recorte, o que pode ser acentuado pelo caráter rotacional dos algoritmos, que operacionalizam os resultados a partir do histórico de buscas dentro do aplicativo. Jaqueline Vasconcellos (2019, p. 25) sinaliza que a função do algoritmo acaba que "[...] delimita as possibilidades de interlocução com o universo daquela rede social, seria imprudente, no que se refere às possibilidades de expansão comunicacional para o meio da arte".

Romper com o domínio fortemente arraigado pressupõe uma pesquisa mais ativa dentro do aplicativo, que vise identificar categorias de imagens ou coleções previamente criadas que subtraiam a limitação dominante. Uma postura crítica do arte/educador é imprescindível em relação à pesquisa, porque é necessário ultrapassar a primeira barreira dos artistas "consagrados", "gênios" ou "grandes mestres”. É com esse propósito que Moura (2017, p. 28) defende o rompimento com os "universalismos alienantes":

O pensar decolonial nos processos de produção de conhecimentos trata de romper com os universalismos alienantes e coloca em pauta, pela análise crítica, os binarismos modernos que inundam as academias: norte/ sul, ocidente/oriente, colonizador/colonizado, rico/pobre, cultura/natureza, branco/negro, homem/mulher, ciência/arte. Por outras vias, trata de pensar co-existências - de mundos, de conhecimentos, de 


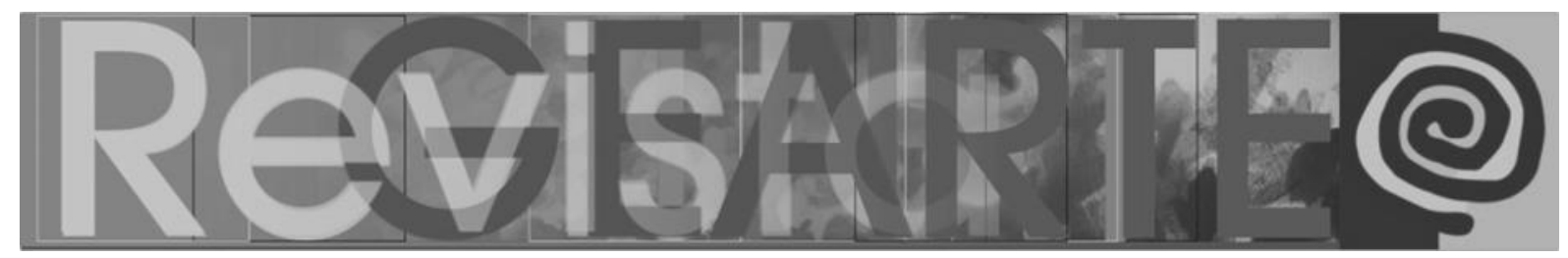

lugares, de povos, de ciências, de artes, de culturas, de pensamentos problematizando as hierarquias, legitimando processos antihegemônicos, imaginando entrelugares e formas outras de produção de conhecimentos.

As dicotomias só poderão ser ultrapassadas se houver material de pesquisa suficiente para que o arte/educador continue desenvolvendo suas práticas. É possível pensar a questão da proporcionalidade do corpo abordando, por exemplo, imagens de gravuras orientais no lugar das já tradicionais imagens do renascimento italiano. Da mesma forma, pode-se falar do conceito de cor e teorizar sobre saturação e círculo cromático utilizando o artista africano Prince Gyasi, em vez do exemplo recorrente nessa temática, Henri Matisse. Não se propõe, com isso, que se desfaça da produção já conhecida e reconhecida da história da arte, mas que haja um olhar ampliado no que diz respeito à formação do professor.

O mecanismo aparentemente aleatório de busca dos algoritmos direciona a pesquisa dos professores e usuários das plataformas de busca, uma vez que o histórico é levado em consideração na disponibilidade de imagens que são apresentadas. De acordo com Vasconcellos (2019, p. 26):

Ao definir uma questão, a função do algoritmo é solucionar o problema, por meio da fragmentação do objeto, e em sequência. O algoritmo é a unidade básica nas ciências da computação. Em questões mais complexas, em plataformas que se utilizam de Inteligência Artificial, se operam diversos conjuntos de algoritmos, inclusive aqueles que 'aprendem' com as alterações feitas no programa.

O modo de busca na solução de problemas reitera respostas mais recorrentes, reforçando, no caso da temática abordada nesse texto, a repetição de um mesmo conjunto de referências. A análise dos algoritmos e da inteligência artificial, como mecanismos das plataformas de pesquisa, podem fazer crer que esse processo seja gerado apenas pela combinação de códigos em máquinas, contudo, é urgente considerar que a programação dos algoritmos é feita, em primeira instância, ao menos, de forma manual, como afirma Vasconcellos (2019, p. 27), "Esses códigos são fruto da atuação de corpos-programadores, que os pensaram e formataram para tentar gerir uma realidade virtual, incluindo respostas geradas pelos 


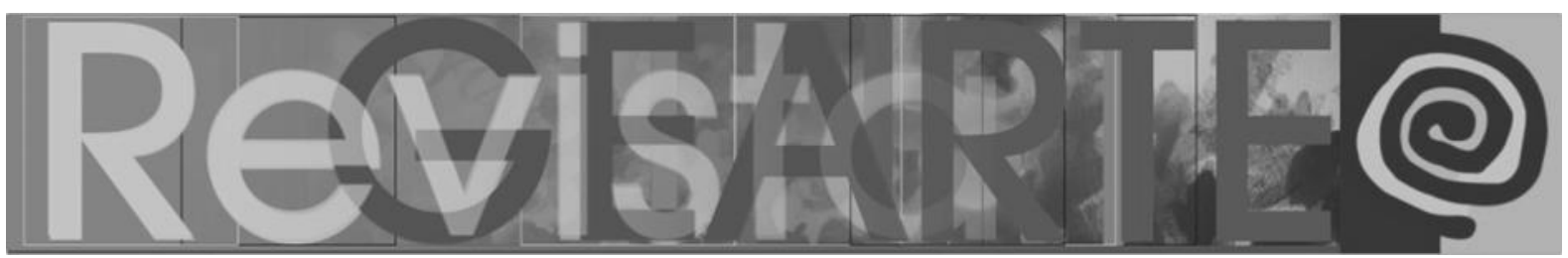

interatores naquele espaço". Assim, o encaminhamento de determinados resultados nas ferramentas de busca ou a recorrência diante do histórico de procura dos usuários é realizado de forma intencional, "[...] a Inteligência Artificial, tal qual compreendemos hoje nas operações computacionais só são possíveis porque um conjunto de cientistas e programadores tentam se aproximar das formas como o cérebro humano pensa" (VASCONCELLOS, 2019, p. 28).

Igualmente, é importante considerar que as redes sociais e plataformas de busca lidam com a tentativa de retenção dos usuários na maior quantidade de tempo possível. A inteligência artificial alimentada com o conjunto de dados busca ofertar ao usuário uma quantidade de informações familiares antes de lançar uma nova referência (que pode gerar a saída do usuário, pelo estranhamento). A recorrência de informações semelhantes mantém o usuário em uso dentro da plataforma, mas, ao mesmo tempo, limita as possibilidades de alcance nos modos de busca.

Para além das questões até então exploradas como limitadoras dos algoritmos, é importante ter em consideração a plataforma Google como empresa, que negocia suas postagens e conteúdos de acordo com o pagamento de anúncios, o que cria uma hierarquização entre as informações disponibilizadas. $O$ advento da internet pode causar uma errônea ideia de que o acesso é ilimitado e que se desfaz das relações de poder na medida em que o processo de globalização da informação atingiu o nível em que estamos. Como reforça Moura (2017, p. 31), a globalização ainda atua "[...] a serviço do sistema-mundo capitalista, tendo a Europa como centro do poder, encobre outras culturas, mas mantém viva a Europa como divindade donde provém o conhecimento e a cultura universalizantes".

É preciso questionar o caráter do discurso hegemônico que envolve a globalização; ter a possibilidade de acesso ao que se está elaborando em diferentes lugares do mundo não supera a dominação epistemológica na qual a 


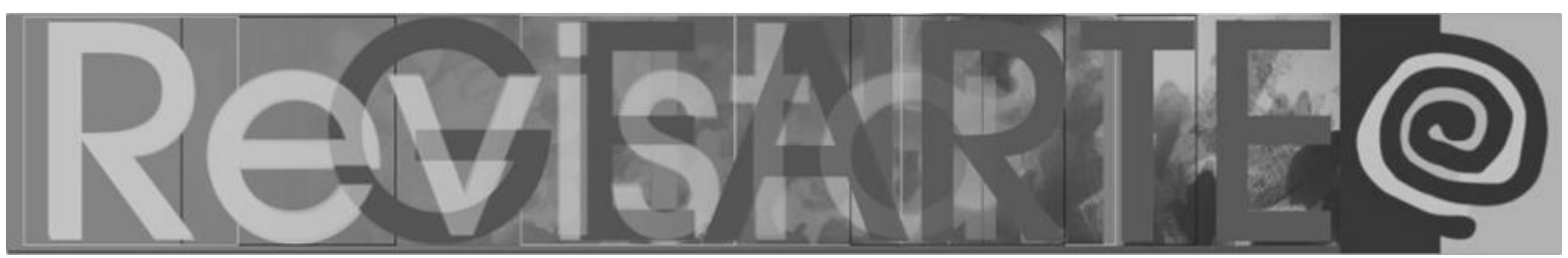

cultura ocidental foi sedimentada. Moura (2017, p. 31) continua, indicando que "Não existe globalização que legitime epistemes latino-americanas, africanas, asiáticas ou mesmo que evidencie essas culturas em cenários globais", por isso, é urgente uma revisão das ferramentas para que haja uma ampliação do olhar dos professores.

A responsabilidade da revisão das fontes atende não somente a uma necessidade por parte da formação do professor, mas é imprescindível sobretudo porque reverbera no desenvolvimento e na aprendizagem dos estudantes. Maria Cristina da Rosa Fonseca da Silva (2005, p. 64) demarca a necessidade de ampliação do olhar por parte dos professores, pensando, em especial, no papel que igualmente ocupam de ampliar o repertório dos seus estudantes, passando por fontes, imagens e obras de todo tipo de procedência e reafirmando a pluralidade de produções no campo da arte:

\begin{abstract}
A qualificação da formação dos professores tem a tarefa de estimulá-los para que ofereçam espaço na aula de arte, onde as futuras gerações ampliem seu contato com a arte. Num processo de alimentar-se de uma produção artística variada, com elementos locais e internacionais, populares e de outros povos, os alunos terão maior visibilidade dos aspectos culturais da humanidade.
\end{abstract}

Em vista desse cálculo direcionado a partir dos modos de busca e do olhar maquinário da escolha das fontes, propõe-se um cuidado em relação ao uso unicamente das tecnologias, especificamente do aplicativo Google Arts and Culture como ferramenta de busca. A partir de Fonseca da Silva (2005, p. 49), reforça-se a necessidade de ampliação das fontes, para abarcar a inclusão de produções que não sejam dominantes, visto que "[...] existe um universo de conteúdos que podem estar presentes no currículo escolar compondo a expansão do universo cultural dos estudantes".

A relação dos professores no consumo ativo de imagens precisa ter em conta um olhar mais ampliado, visando identificar referências visuais que estejam para além das comumente identificadas pelas ferramentas de busca. As 


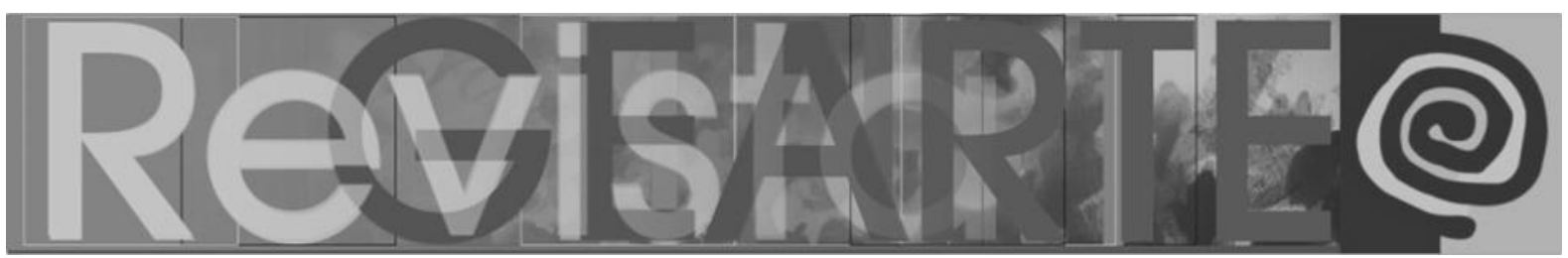

perspectivas de pesquisa precisam ser amplas para identificarem a seleção das imagens a partir de um recorte que não se centre unicamente nos artistas e nas produções acessíveis aos estudantes ou publicadas nos livros didáticos.

Haja vista que um dos objetivos das práticas formativas do ensino da arte esteja imbricado com a relação com as imagens, propondo leituras delas e sua identificação como objetos de discurso, é importante que o olhar seja ampliado e aberto a variadas perspectivas. "Cabe ressaltar que este aprofundamento cultural deve ser construído por meio de uma formação sólida do professor que considere os aspectos históricos, sociológicos, antropológicos, educacionais e artísticos" (FONSECA DA SILVA, 2005, p. 49-50). Contemplar esses diferentes aspectos é um desafio para o processo formativo do professor, bem como para sua atuação no planejamento e proposição dos exercícios.

Enquanto as fontes de referência, as aulas de história da arte e as fontes de informação ainda estiverem muito centradas no reflexo do processo de dominação vivenciado, caberá ao professor buscar formas de abarcar novos meios de construção do repertório de imagens. Forte (2011, p. 831) afirma que cabe aos professores em formação a função de "[...] invadir esses espaços 'fechados' para que o conhecimento adquirido na disciplina não seja trabalhado com seus alunos da maneira linear, assim como a que receberam e nem determinando um valor excludente de outros meios visuais". As ferramentas tecnológicas podem ser grandes aliadas nesse processo, desde que se consiga colocar em causa o processo mecânico dos algoritmos. 


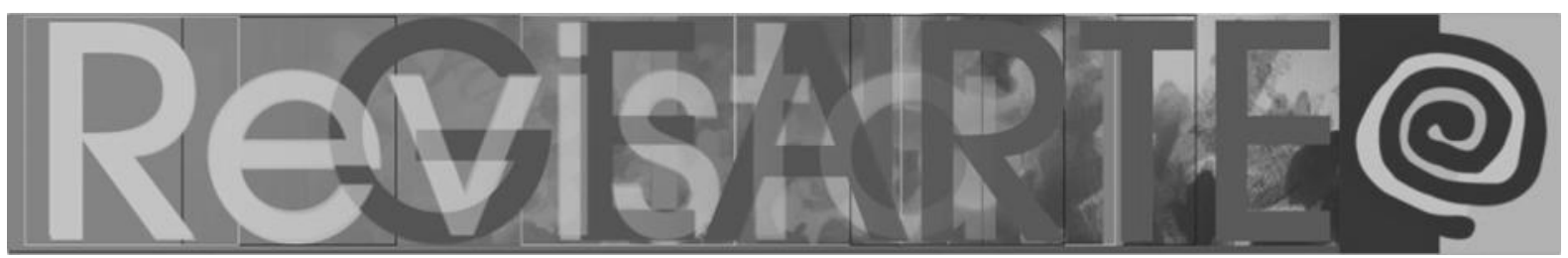

\section{Notas}

1 As instituições presentes no aplicativo no momento de redação do texto são: Pinacoteca do Estado de São Paulo, Museu Lasar Segall, Museu Paulista, Museu de Arte de São Paulo, Museu de Arte Moderna de São Paulo, Museu Afro Brasil, Centro Cultural São Paulo, Casa Guilherme de Almeida, Fundação Ema Klabin, Museu da Imagem e do Som, Centro Cultural Banco do Brasil de São Paulo, Instituto Tomie Ohtake, Fundação Bienal, Itaú Cultural e Instituto URBE, do estado de São Paulo; Museu Nacional de Belas Artes, Museu de Arte Moderna do Rio de Janeiro, Museu Imperial, Instituto Moreira Salles, Centro Cultural Banco do Brasil do Rio de Janeiro, Projeto Portinari, Museu Histórico Nacional e Museu Castro Maya, do estado do Rio de Janeiro; Instituto Inhotim, Centro Cultural Banco do Brasil de Belo Horizonte e Instituto Terra, do estado de Minas Gerais; Centro Cultural Banco do Brasil de Brasília e Fundação Athos Bulcão, do Distrito Federal; Museu de Arte Moderna Aloísio Magalhães e Paço do Frevo, do estado de Pernambuco; Museu Oscar Niemeyer, do estado do Paraná; e Fundação Iberê Camargo, do estado do Rio Grande do Sul. Levantamento realizado em julho de 2021.

2 Pela amplitude de conexões possíveis de se estabelecer na ideia de arte e cultura que o aplicativo propõe, estão incluídas também outras tipologias de museus e instituições culturais para além das instituições voltadas para a promoção das artes visuais, como, por exemplo, Museu do Futebol, Museu da Língua Portuguesa, Instituto Sócio-ambiental de São Paulo, Museu da Pessoa, Fundação Theatro Municipal de São Paulo, Museu do Café, Biblioteca Mário de Andrade, Instituto Vladmir Herzog, Museu do Amanhã, Museu da Moda Brasileira, Instituto Ziraldo, Theatro Municipal do Rio de Janeiro, Conservação Rio, Musica Brasilis, Projeto Tamar e Kanindé - Associação de Defesa Etnoambiental. Dentro desta análise, contudo, privilegiaremos o debate em torno de museus direcionados para a produção artística e visual.

\section{Referências}

ACASO, María. La educación artística no son manualidades: nuevas prácticas en la enseñanza de las artes y la cultura visual. Madrid: Editora Catarata, 2009.

ACASO, María; MEGÍAS, Clara. Art thinking - cómo el arte puede transformar la educación. Barcelona: Paidós educación, 2017.

FONSECA DA SILVA, Maria Cristina da Rosa. A formação de professores de Arte: diversidade e complexidade pedagógica. Florianópolis: Insular, 2005.

FORTE, Marcelo. Repertório visual na formação do professor de Artes Visuais. In: Anais do Encontro da Associação Nacional de Pesquisadores em Artes Plásticas - 26 de setembro à 01 de outubro de 2011. Rio de Janeiro: ANPAP, 2011.

MOURA, Eduardo. Inquietações, decolonialidade e desobediência docente formação inicial de professores/as. Revista Papeles. Bogotá, v. 9, n 18, jul./dez., 2017.

VASCONCELLOS, Jaqueline Reis. Intersecções entre Arte/Audiovisual|Emancipação: Vimos dizer um discurso! 2019. Tese (Doutorado em Meios e Processos Audiovisuais) - Escola de Comunicação e Artes, Universidade de São Paulo, São Paulo, 2019.

SOUZA, Any Karoliny Wutke. Potencialidades do uso do celular no ensino da arte: uma reflexão a respeito da juventude, da escola e do ensino da arte contemporânea. 2019. Trabalho de conclusão de curso (Graduação). Licenciatura em Artes Visuais. Universidade Federal do Espírito Santo, Vitória, 2019. 


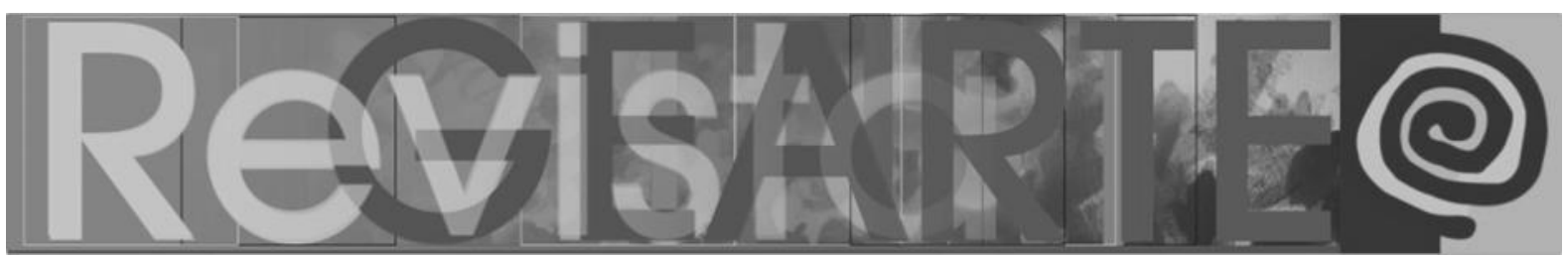

Julia Rocha

Doutora em Educação Artística pela Universidade do Porto, Mestre em Artes e Educação pela Universidade Estadual Paulista e Licenciada em Artes Plásticas pela Universidade do Estado de Santa Catarina. Professora da Universidade Federal do Espírito Santo. Coordenadora do Grupo de Pesquisa Entre - Educação e arte contemporânea (CE/UFES) e do Núcleo de Artes Visuais e Educação do Espírito Santo - NAVEES. Realiza pesquisa sobre o ensino da arte na contemporaneidade, mediação cultural, relações entre museus e escolas, avaliação de propostas educativas no campo das artes visuais e formação de professores.

ORCID: https://orcid.org/0000-0001-9135-5912

E-mail: pjuliarocha@gmail.com

Currículo: http://lattes.cnpq.br/1973788294795614

\section{Any Karoliny Wutke Souza}

Professora de artes no ensino básico da rede municipal de Serra - ES. Licenciada em Artes Visuais pela Universidade Federal do Espírito Santo (UFES). Participa do Grupo de Pesquisa Entre Educação e arte contemporânea (CE/UFES). Realiza pesquisa e tem interesse na área do ensino da arte e arte contemporânea e as relações desses campos com as novas tecnologias.

ORCID: https://orcid.org/0000-0002-2706-8916

E-mail: karolwutkes@gmail.com

Currículo: http://lattes.cnpq.br/9752158027453374

Recebido em 31 de julho de 2021 Aceito em 16 de novembro de 2021 